\title{
The importance of amino acids in the adult diet of male tropical rainforest butterflies
}

\author{
Jan Beck
}

Received: 2 August 2006 / Accepted: 2 November 2006 / Published online: 22 February 2007

(C) Springer-Verlag 2007

\begin{abstract}
Adult diet is a major factor contributing to life history variation in the Lepidoptera. Amino acids derived from adult feeding, in particular, are suspected to be a major contribution to fitness, but this could be proven in only few species so far. Effects of amino acids in the diet of butterflies were experimentally investigated in 13 species from a Borneo rainforest community (using caged males without mating opportunity). Four species lived substantially longer when given a mix of amino acids additionally to water, sodium and sugar solutions. No significant phylogenetic pattern was found for effects of amino acid feeding, although none of six pierid species were among the taxa with significant effects. Species that do react to amino acids tend to be among the most long-lived taxa in the community, suggesting that amino acids are a key variable to attain long life spans. Weaker effects, or impacts on other fitness-related variables, cannot be excluded in the remaining taxa. Results indicate that adult amino acid intake may not be a rare strategy of few exotic
\end{abstract}

Communicated by Konrad Fiedler.

J. Beck $(\bowtie)$

Kuala Belalong Field Studies Centre,

Universiti Brunei Darussalam, Tungku Link,

Gadong, BE1410, Brunei

e-mail: jan.beck@gmx.net

Present Address:

J. Beck

Department of Environmental Sciences,

Biogeography Section, University of Basel,

St. Johanns-Vorstadt 10, 4056 Basel, Switzerland taxa, but is, at least in non-seasonal tropical regions, a common life history trait in a substantial number of butterfly species.

Keywords Adult feeding $\cdot$ Fitness $\cdot$ Life history $\cdot$ Lepidoptera $\cdot$ Longevity

\section{Introduction}

Recent studies on the variation in life history variables (cf. Stearns 1977) involved organisms as different as insects (Nylin and Gotthard 1998), bats (Wilkinson and South 2002), birds (Martin 1995) and humans (Kaplan et al. 2000). Diet has often been identified as an important variable influencing physical development, whereas other factors, such as mortality or the mating system, may also interact with the evolution of life histories.

The utilization of food resources in adult Lepidoptera has long been recognized as an important parameter of life history variability in this group, allowing researchers to study trade-offs between various strategies (Boggs 1997; Jervis et al. 2005) as well as their evolutionary causes and ecological consequences (e.g. Janzen 1984; Hill and Pierce 1989; Tammaru and Haukioja 1996). A large variety in adult feeding habits is known from nocturnal moths [ranging from non-feeding (e.g. Janzen 1984), to blood-sucking (e.g. Bänziger 1986)], whereas among diurnal butterflies pollen-feeding Heliconius species (e.g. Erhardt and Baker 1990) were long seen as rare examples of species utilizing amino acids among a group of mostly flower-visiting species that just replenish energy (i.e. sugars) by adult feeding. Rotting fruits are an alternative food source 
for a predominantly tropical guild of species (e.g. Krenn et al. 2001), but their importance as a source of amino acids is as yet unknown (Fischer et al. 2004).

However, indirect evidence has accumulated that amino acids my play a greater role in butterfly feeding. For example, butterfly-visited flowers were found to contain more amino acids in their nectar than other flowers (Baker and Baker 1973), some butterfly species are able to discriminate for nectar rich in amino acids (e.g. Erhardt and Rusterholz 1998; Mevi-Schütz and Erhardt 2004), and rotting protein is sought for by some species in the behavioural context of mud-puddling (Beck et al. 1999; Boggs and Dau 2004). Recently, Mevi-Schütz and Erhardt (2005) could prove fitness effects of amino acids from nectar feeding in a European species, whereas not in all investigated taxa could such effects be found (e.g. Romeis and Wäckers 2002; see also Kaitala and Wiklund 1994; Wedell 1996 for effects of nitrogen received by mating).

In this paper I report the results of an experimental investigation on the effect of adult amino acid feeding on the longevity of butterfly species from a tropical rainforest assemblage. Very little is known about butterfly life spans in tropical taxa [6 weeks and more were reported for single individuals of fruit-feeding species (Beck and Schulze 2000; Tangah et al. 2004)], and it has been argued that weak seasonality might give selective advantage to long-lived species (Beck et al. 1999). Specifically, I address the questions: (1) whether amino acid feeding increases longevity (a fitness-related parameter, see Discussion) in any species, (2) how common such effects are among the local species assemblage, and (3) how such effects relate to the phylogeny as well as some ecological traits of species (i.e. morphology, adult and larval feeding).

\section{Materials and methods}

Study site, acquisition and identification of specimens

The study was carried out at Kuala Belalong Field Study Centre (KBFSC; Brunei, northern Borneo; $4^{\circ} 33^{\prime} \mathrm{N}, 115^{\circ} 09^{\prime} \mathrm{E}$, ca. $50 \mathrm{~m}$ a.s.l.), surrounded by virgin lowland rainforest (Cranbrook and Edwards 1994). Diversity patterns and phenology of the butterfly assemblage at KBFSC have been studied by Orr and Haeuser (1996), who reported 324 species, or $34 \%$ of the described species richness of Borneo, in ca. $1 \mathrm{~km}^{2}$ of forest around the field centre.

Adult specimens were caught with a butterfly net at KBFSC and surrounding forest between June 2005 and
July 2006; mud-puddling species were sampled along the river bank. All species within reach were sampled, with the exception of the blue-winged members of the lycaenid tribe Polyommatini and the nymphalid genus Tanaecia, as species identification in these groups (especially in living or old specimens) is exceedingly difficult.

Specimens were carefully packed in glossy paper and transported in a plastic box to the field centre. They were kept individually (without the opportunity to mate) in cages varying in size from $20 \times 20 \times 30 \mathrm{~cm}$ to $2 \times 2 \times 2 \mathrm{~m}$, depending on the size and flight activity of species. Terrariums were placed under a roof on a shady veranda, hence under natural climate conditions. Only specimens without any sign of wing wear (an indicator of age; e.g. Kemp 2001) were used to diminish biases due to pre-catch age and feeding differences. Furthermore, data of specimens that died within $24 \mathrm{~h}$ after catch were excluded from analyses, as they might have been injured during catch or transport (less than five cases). Cages were inspected daily for dead specimens, whereas feeding solutions were replaced every 4-5 days; the extremely high humidity in the steep, forested valley prevented most evaporation of feeding fluids.

Specimens were preliminarily identified after being caught, whereas determination was verified after death on pinned specimens, using literature by Otsuka (1988), Seki et al. (1991) and Corbet and Pendlebury (1992); specimens are deposited at KBFSC. Species were classified according to behavioural and dietary traits (i.e. male territoriality, natural adult and larval feeding) based on my observations and information given in Corbet and Pendlebury (1992) and Robinson et al. (2001).

The use of field-sampled adults, rather than larval rearing (which was not feasible under local conditions), introduces slight errors in absolute life span measures despite restriction to fresh-looking specimens, but there are no reasons to expect biased comparisons as specimens were assigned randomly to experimental treatment groups (data for species where this condition was not met were excluded, see Discussion).

\section{Experimental feeding}

Four types of feeding solution were used for feeding experiments:

1. Deionized water.

2. Sodium solution $(0.1 \mathrm{~mol} / \mathrm{l}$ sodium chloride; all solutions in deionized water). Sodium is a rare 
mineral for herbivorous insects and is actively sought for in some butterfly species (particularly Lycaenidae, some Papilionidae; e.g. Beck et al. 1999).

3. Sucrose solution (commercially available white sugar, 25\%). This type of sugar and concentration is found in many flower nectars, it has been used before in similar experimental set-ups (e.g. Rusterholz and Erhardt 1997, and references therein), and preferences for sucrose have been shown in butterflies (e.g. Romeis and Wäckers 2000).

4. Amino acids (in total $1.6 \mathrm{~g}$ per $100 \mathrm{ml}$ sucrose solution); $0.1 \mathrm{~g}$ per $100 \mathrm{ml}$ of each of 16 available, crystalline amino acids (leucin, cystein, glutamin, alanin, phenylalanin, threonin, prolin, glutamic acid, thyrosin, valin, histidin, glycin, methionin, aspargine, serin, arginine) were used. Amino acids were mixed in sucrose solution to account for the possibility that species might not be able to taste (hence find) them, but imbibe them in nature as a side-effect of specific flower preferences (Romeis and Wäckers 2000). Mimics of Lantana nectar (an amino acid-rich flower) have been used in various studies (Mevi-Schütz and Erhardt 2005, and references therein), adding up to $0.525 \mathrm{~g}$ per $100 \mathrm{ml}$. Thus, the solution used here is probably richer than many natural sources, but of a similar order of magnitude.

Food solutions were placed in Petri dishes with a piece of coloured paper tissue as a visual cue, a suitable method for stimulating feeding behaviour in butterflies (e.g. Beck et al. 1999; feeding was observed in all species). A control group of specimens had access to all four types of feeding solution, whereas an experimental group was deprived of amino acid solution, but had access to water, sodium and sugar. Experimental treatment was carried out only in species that were common enough to attain sufficient sample sizes for analysis. Forewing lengths (FWL) and thorax widths were measured with a calliper on at least five specimens per species, wing loads (a proxy for flight strength) were estimated as thorax width/FWL (assuming constant muscle mass per thorax width, and constant wing area per FWL).

Standard parametric statistics were used to test for differences in longevity between experimental and control groups within each species (StatSoft 2005), accounting for unequal variances if necessary. Power analysis (i.e. type 2 error estimate) was carried out with software by Faul and Erdfelder (1992).

A randomization test [Runs test (Abouheif 1999), software by Reeve and Abouheif (2003)] was used to detect an impact of phylogeny on reaction vs. nonreaction to amino acid feeding. A phylogeny of species was taken from higher-taxon phylogenies (Wahlberg et al. 2005) and genus classifications (Corbet and Pendlebury 1992), allowing for unresolved nodes where applicable.

\section{Results}

Of $>500$ suitable specimens and $>100$ species, only 13 species were common enough to make experimental treatment feasible (five or more specimens in each treatment group, all male). Figure 1 display survival times of experimental and control groups in all species. Survival times of the 13 species range from 2 days to over 4 weeks, covering almost the entire range of longevity found for any species in this habitat. While deprivation of amino acids reduced longevity in most investigated taxa, effects are statistically significant in only four species (Table 1). In these species, reductions in mean survival amount to $34-79 \%$ (i.e. ca. $2-11$ days) of mean control group longevity, depending on species.

Data from Table 1 were used to classify species as "reacting" $(P \leq 0.05)$ and "non-reacting" to amino acid feeding (Fig. 2). The Runs test indicated no significant phylogenetic signal in data $(10,000$ randomizations, $P=0.160)$. An alternative analysis based on standardized effect sizes (Hedges' $d$ ) rather than a binary classification also suggested phylogenetic independence of data (not shown). As a methodological consequence of these results, I did not consider phylogenetic effects in cross-species comparisons (paragraph below), following arguments by Pocock et al. (2006).

Species that show reactions to adult amino acid feeding had greater mean life spans (under control conditions, log-transformed; $t_{d f=11}=4.69, P<0.001$ ). There are no significant differences in mean size (FWL, Thorax) or wing load between reacting and non-reacting species $(t$-tests, two-sided, separate variance estimates: $n=13, t<1.6, P>0.20)$. Despite a trend, groups do not significantly differ in proportions for species commonly engaged in mud-puddling and those that do not $\left(2 \times 2\right.$ table, $\left.\chi_{d f=1}^{2}=5.3, P_{\text {exact }}=0.052\right)$. Species known to feed on legumes in their larval stage (missing data in some species were substituted by host plant records for congeneric butterflies, whereas no information was available for Paralaxita) are not less likely to react $\left(\chi_{d f=1}^{2}=2.0, P=0.49\right)$. Thus, I found no indication (among 12 species) that effects of "compensatory" adult feeding (cf. Mevi-Schütz and Erhardt 2005) also play an inter-specific role. Fruit feeding (F. gracilis, $R$. makuta) and taxa with strong territorial behaviour 
Fig. 1 Mean adult longevity ( \pm SE, minimum-maximum) with control (amino acid) and experimental (no amino acid) feeding for male butterflies of 13 species. (See Table 1 for statistical tests and species names)
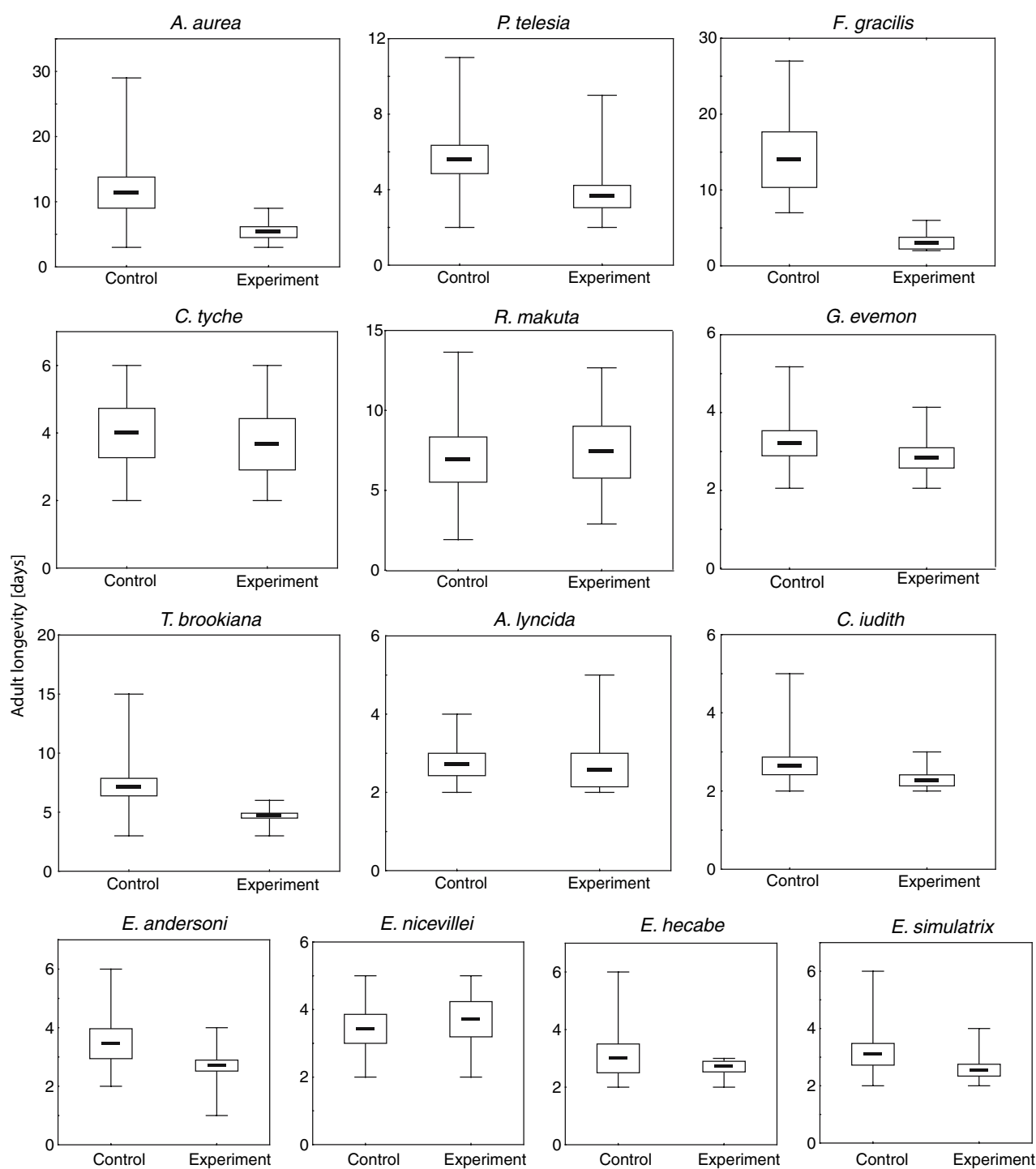

(A. aurea, P. telesia) were too few to test for relationships of respective traits with amino acid utilization. However, both traits are generally associated with long life spans in the investigated community (J. Beck, unpublished data).

\section{Discussion}

Substantially increased adult longevity due to amino acid feeding was shown in four out of the 13 most commonly encountered species in the habitat, stressing the importance of amino acids in the diet of probably many rainforest butterflies. Furthermore, given that species that react to amino acids appear generally longer-lived than other taxa, it seems likely that amino acids are a key variable to increase life span in butterflies (as has been suggested in Heliconius; Erhardt and Baker
1990). Physiological aspects of aging in Lepidoptera, indeed most insects, remain largely unknown (Hughes and Reynolds 2005), particularly with regards to diet quality.

In the limited cross-species comparison presented here, no significant phylogenetic effects could be found, nor could any other hypotheses related to body size, wing load, territoriality and adult or larval diet be confirmed. However, it is suggestive that not only did no pierid species show an effect of amino acid feeding, but they also generally have the shortest life spans among the $>100$ species studied from this rainforest assemblage (J. Beck, unpublished data). Similarly, fruit-feeding species as well as (territorial) Lycaenidae are amongst the most long-lived taxa, hinting that probably many of these species utilize adult-acquired amino acids. Most papilionid species were too scarce to make similar generalizations, except that various members of 
Table 1 Species' taxonomic affiliation, sample sizes $(N)$ and results of two-tailed $t$-tests for differences in mean survival times between control ("contr."; i.e., with amino acid) and experimental ("exp."; i.e., without amino acid) feeding

\begin{tabular}{|c|c|c|c|c|c|c|}
\hline Family & Subfamily & Species & $N_{\text {exp }}$ & $N_{\text {contr }}$ & $t_{(d f)}$ & $P$ \\
\hline \multirow[t]{2}{*}{ Lycaenidae } & Lycaeninae & Arhopala aurea & 9 & 10 & $2.30_{(17)}$ & 0.035 \\
\hline & Riodininae & Paralaxita telesia & 11 & 10 & $2.08_{(19)}$ & 0.051 \\
\hline \multirow[t]{3}{*}{ Nymphalidae } & Morphinae & Faunis gracilis & 5 & 5 & $2.94_{(8)}$ & 0.019 \\
\hline & Nymphalinae & Cirrochroa tyche & 6 & 6 & $0.32_{(10)}$ & 0.758 \\
\hline & Satyrinae & Ragadia makuta & 5 & 8 & $-0.21_{(11)}$ & 0.837 \\
\hline \multirow[t]{2}{*}{ Papilionidae } & Papilioninae & Graphium evemon & 8 & 9 & $0.89_{(15)}$ & 0.386 \\
\hline & & Troides brookiana & 17 & 19 & $3.23(31)$ & 0.003 \\
\hline \multirow[t]{6}{*}{ Pieridae } & Coliadinae & Eurema andersoni & 17 & 11 & $* 1.38_{(13)}$ & 0.193 \\
\hline & & Eurema hecabe & 7 & 8 & $0.51_{(13)}$ & 0.621 \\
\hline & & Eurema nicevillei & 7 & 7 & $-0.42_{(12)}$ & 0.680 \\
\hline & & Eurema simulatrix & 11 & 10 & $1.32_{(19)}$ & 0.203 \\
\hline & Pierinae & Appias lyncida & 7 & 7 & $0.28_{(12)}$ & 0.786 \\
\hline & & Cepora iudith & 11 & 14 & $1.31_{(23)}$ & 0.205 \\
\hline
\end{tabular}

Data assumptions of parametric tests have been checked (not shown); $t$-tests for separate variance estimates were used where applicable (*Levene tests, $P<0.05$ ). A total sample size of $N=18$ is necessary to find a strong effect (Hedge's $d=1$; all significant tests had $d \geq 0.9$ ) with a power $>0.5$; a sample size of 24 enhances power to 0.65 . Means and variation of survival data are shown in Fig. 1 . Note that, under the assumption that amino acids can only lead to positive effects on life span in the current experimental design (as supported by data, Fig. 1), one-tailed tests may be appropriate

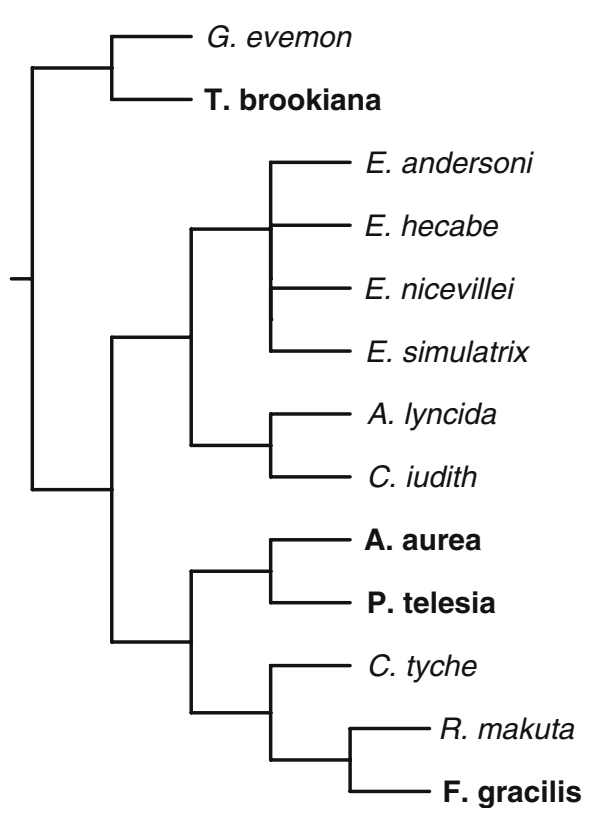

Fig. 2 Phylogeny of species under investigation. Species in bold react to amino acids in their adult diet (Table $1, P \leq 0.05$ ), species in italics do not

the Graphium/Pathysa group were all relatively shortlived.

Is adult life span fitness-relevant?

Adult nutrients can contribute to the fitness of Lepidoptera in a variety of ways: they can promote and prolong egg production in the female (Boggs 1997), they can be "collected" by males and transferred to the female during mating (e.g. O'Brian et al. 2003; MeviSchütz and Erhardt 2004), they can be used by males to enhance sexually selected traits (e.g. pheromone production) and thereby lead to higher mating success (e.g. Schneider 1993), or they can prolong life in both sexes. This may be fitness-relevant in pre-ovipositing females (cf. Nylin et al. 2000) or species with continuous egg production. Bauernfeind and Fischer (2005) report positive correlations between adult longevity and lifetime fecundity in captive females of an Afrotropical butterfly. Males might profit due to higher mating success. The data presented here only allow investigation of the latter effect, as there were not enough females available to study. Furthermore, subtle effects such as an increase in fitness only in specimens with poor larval diet (e.g. Mevi-Schütz and Erhardt 2005) could also not be studied. Lastly, because of sample size constraints (Table 1) weaker effects on longevity might have been overlooked due to a lack of statistical power. Thus, it is important to stress that species showing no effect of amino acid feeding on male longevity might still benefit in other ways.

For most species studied here, no background information on their mating and reproduction biology is available, with the exception of some preliminary data on $A$. aurea (see Beck and Wagner 2006 for details). Males of this species vigorously defend little territories, probably mating-related "leks" (cf. Fischer and Fiedler 2001; Kemp 2001). However, despite intense observation not a single successful mating was recorded, and only two potential $A$. aurea females were seen. Females are apparently very rare and possibly unpredictable in 
occurrence, and only long-lived males might have any chance of mating (cf. Gotthard et al. 2000). Observations suggest a similar mating system in $P$. telesia, but less detailed data are available for this species.

What are natural sources of amino acids?

Very little is known about natural sources of amino acids for adult rainforest butterflies. As indicated above, butterfly-visited flowers may be a major source of amino acids (e.g. Blüthgen and Fiedler 2004), but observations of butterflies feeding naturally in the rainforest are exceedingly rare. Rotting fruits may provide a rich source of amino acids, as indicated by long life spans in species utilizing this resource (J. Beck, unpublished data), but their unpredictability of occurrence might also have selected for longevity irrespective of food quality. I found a positive effect of amino acids in only one of the two available fruit-feeding taxa, whereas Bauernfeind and Fischer (2005) report reduced longevity (but higher fecundity) in amino acidfed female specimens in an Afrotropical nymphalid. Data for two further fruit-feeding species (Lexias pardalis, Thauria aliris; not shown) indicated a similar reaction, but were excluded from analyses because of differences in pre-experimental feeding that might have artefactually caused this effect.

Protein-related "mud-puddling" (including carrion, excrements, etc.) appears an obvious source of amino acids, but I could not, unfortunately, test directly for effects in species known for this feeding habit on Borneo (Beck et al. 1999). For Caleta elna (Lycaenidae) and various hesperiid species (all showing a strong preference for protein-puddling; Beck et al. 1999), short life spans suggest benefits other than increased longevity. Furthermore, additional experiments (data not shown) suggest that $T$. brookiana does not derive its amino acids from decaying protein at mud-puddling, which apparently serves the intake of a yet unknown substance in this species (cf. Beck et al. 1999).

\section{Conclusion}

Amino acids in the adult diet of rainforest butterflies have strong effects on the longevity, hence fitness, of about a quarter of studied species, whereas weaker effects or impact on other fitness-related variables cannot be excluded in the remaining taxa. Thus, fitnessrelevant adult amino acid intake is not a rare strategy of a few exotic taxa, but might be, at least in tropical regions, a common life history trait in a substantial number of butterfly species. Most likely, such effects will be found among the relatively long-lived species.
More detailed studies will be needed to find natural sources of amino acids and details on their contribution to fitness in single species, and to understand evolutionary trade-offs of such effects in cross-species comparisons (i.e. when is increased life span of selective advantage, and when not; e.g. Hughes and Reynolds 2005).

Acknowledgements I thank the staff of KBFSC, as well as J.-P. Lessard, A. Keller and K. Wagner for help with routine laboratory work. Furthermore, I am grateful to N. Blüthgen for supplying amino acids, and to K. Fiedler for advice on butterfly keeping. K. Fiedler and two anonymous reviewers made helpful comments on an earlier draft of the manuscript. The study was financed by a Research Fellowship of Universiti Brunei Darussalam.

\section{References}

Abouheif E (1999) A method for testing the assumption of phylogenetic independence in comparative data. Evol Ecol Res 1:895-909

Baker HG, Baker I (1973) Amino acids in nectar and their evolutionary significance. Nature 241:543-545

Bauernfeind SS, Fischer K (2005) Effects of adult-derived carbohydrates, amino acids and micronutrients on female reproduction in a fruit-feeding butterfly. J Insect Physiol 51:545554

Bänziger H (1986) Skin-piercing blood-sucking moths IV: biological studies on adults of 4 Calyptra species and 2 subspecies (Lep., Noctuidae). Mitt Schweiz Entomol Ges 59:111-138

Beck J, Schulze CH (2000) Diversity of fruit-feeding butterflies (Nymphalidae) along a gradient of tropical rainforest succession in Borneo with some remarks on the problem of "pseudoreplicates". Trans Lepidopt Soc Jpn 51:89-98

Beck J, Wagner K (2006) Observations on the territoriality of male Arhopala aurea, a lycaenid butterfly of the rainforest understorey. Sepilok Bull 5:17-25

Beck J, Mühlenberg E, Fiedler K (1999) Mud-puddling behavior in tropical butterflies: in search of protein or minerals? Oecologia 119:140-148

Blüthgen N, Fiedler K (2004) Preferences for sugars and amino acids and their conditionality in a diverse nectar-feeding ant community. J Anim Ecol 73:155-166

Boggs CL, Dau B (2004) Resource specialization in puddling Lepidoptera. Environ Entomol 33:1020-1024

Boggs CL (1997) Reproductive allocation from reserves and income in butterfly species with differing adult diets. Ecology 78:181-191

Corbet AS, Pendlebury HM (1992) The butterflies of the Malay peninsula, 4th edn (revised by JN Eliot). Malayan Nature Society, Kuala Lumpur

Cranbrook E, Edwards DS (1994) A tropical rainforest-the nature of biodiversity in Borneo at Belalong, Brunei. Royal Geographic Society, London, Sun Tree Publishing, Singapore

Erhardt A, Rusterholz H-P (1998) Do Peacock butterflies (Inachis io L.) detect and prefer nectar amino acids and other nitrogenous compounds? Oecologia 117:536-542

Erhardt A, Baker I (1990) Pollen amino acids-an additional diet for a nectar feeding butterfly? Plant Syst Evol 169:111-121 
Faul F, Erdfelder E (1992) GPOWER: a priori, post-hoc, and compromise power analysis for MS-DOS (computer program). Bonn University, Department of Psychology, Bonn

Fischer K, Fiedler K (2001) Resource-based territoriality in the butterfly Lycaena hippothoe and environmentally induced behavioural shifts. Anim Behav 61:723-732

Fischer K, O'Brien DM, Boggs CL (2004) Allocation of larval and adult resources to reproduction in a fruit-feeding butterfly. Funct Ecol 18:656-663

Gotthard K, Nylin S, Wiklund C (2000) Mating opportunity and the evolution of sex-specific mortality rates in a butterfly. Oecologia 122:36-43

Hill CJ, Pierce NE (1989) The effect of adult diet on the biology of butterflies. 1. The common imperial blue, Jalmenus evogoras. Oecologia 81:249-257

Hughes KA, Reynolds RM (2005) Evolutionary and mechanistic theories of aging. Annu Rev Entomol 50:421-445

Janzen DH (1984) Two ways to be a tropical big moth: Santa Rosa saturniids and sphingids. In: Dawkins R, Ridley $M$ (eds) Oxford surveys in evolutionary biology, vol 1. pp 85140

Jervis M, Boggs CL, Ferns PN (2005) Egg maturation strategy and its associated trade-offs: a synthesis focusing on Lepidoptera. Ecol Entomol 30:359-375

Kaitala A, Wiklund C (1994) Polyandrous female butterflies forage for matings. Behav Ecol Sociobiol 35:385-388

Kaplan H, Hill K, Lancaster J, Hurtado AM (2000) A theory of human life history evolution: diet, intelligence, and longevity. Evol Anthrop 9:156-184

Kemp DJ (2001) Age-related site fidelity in the territorial butterfly Hypolimnas bolina (L.) (Lepidoptera: Nymphalidae). Aust J Entomol 40:65-68

Krenn HW, Zulka KP, Gatschnegg T (2001) Proboscis morphology and food preferences in nymphalid butterflies (Lepidoptera: Nymphalidae). J Zool 254:17-26

Martin TE (1995) Avian life history evolution in relation to nest sites, nest predation and food. Ecol Monogr 65:101-127

Mevi-Schütz J, Erhardt A (2004) Mating frequency influences nectar amino acid preference of Pieris napi. Proc R Soc Lond B 271:153-158

Mevi-Schütz J, Erhardt A (2005) Amino acids in nectar enhance butterfly fecundity: a long-awaited link. Am Nat 165:411-419

Nylin S, Bergström A, Janz N (2000) Butterfly host plant choice in the face of possible confusion. J Insect Behav 13:469-482

Nylin S, Gotthard K (1998) Plasticity in life history traits. Annu Rev Entomol 43:63-83

O'Brian DM, Boggs CL, Fogel ML (2003) Pollen feeding in the butterfly Heliconius charitonia: isotopic evidence for essential amino acid transfer from pollen to eggs. Proc R Soc Lond B 270:2631-2636
Orr AG, Haeuser CL (1996) Temporal and spatial patterns of butterfly diversity in a lowland tropical rainforest. In: Edwards DS, Booth WE, Choy SC (eds) Tropical rainforest research-current issues. Kluwer, Drodrecht, pp 125-138

Otsuka K (1988) Butterflies of Borneo, vol 1. Tobishima, Tokyo

Pocock MJO, Hartley S, Telfer MG, Preston CD, Kunin WE (2006) Ecological correlates of range structure in rare and scarce British plants. J Ecol 94:581-596

Reeve J, Abouheif E (2003) Phylogenetic independence, v 2.0. Department of Biology, McGill University (distributed freely by the authors on request)

Romeis J, Wäckers FL (2000) Feeding responses by female Pieris brassicae butterflies to carbohydrates and amino acids. Physiol Entomol 25:247-253

Romeis J, Wäckers FL (2002) Nutritional suitability of individual carbohydrates and amino acids for adult Pieris brassicae. Physiol Entomol 27:148-156

Robinson GS, Ackery PR, Kitching IJ, Beccaloni GW, Hernández LM (2001) Hostplants of the moth and butterfly caterpillars of the oriental region. Natural History Museum, London, Southdene Sdn Bhd, Kuala Lumpur

Rusterholz H-P, Erhardt A (1997) Preferences for nectar sugars in the peacock butterfly, Inachis io. Ecol Entomol 22:220 224

Schneider D (1993) Danaine butterflies: a didactic story about chemical ecology. In: Malcolm SB, Zalucki MP (eds) Biology and conservation of the monarch butterfly. Natural History Museum, Los Angeles, Calif., pp 19-28

Seki Y, Takanmi Y, Otsuka K (1991) Butterflies of Borneo, vol. 2, no 1: Lycaenidae. Tobishima, Tokyo

StatSoft (2005). Statistica 7.1. Computer program and manual. StatSoft, Tulsa, Okla.. http://www.statsoft.com

Stearns SC (1977) The evolution of life history traits: a critique of the theory and review of the data. Annu Rev Ecol Syst 8:145-171

Tammaru T, Haukioja E (1996) Capital breeders and income breeders among Lepidoptera-consequences to population dynamics. Oikos 77:561-564

Tangah J, Hill JK, Hamer KC, Dawood MM (2004) Vertical distribution of fruit-feeding butterflies in Sabah, Borneo. Sepilok Bull 1:15-25

Wahlberg N, Braby MF, Brower AVZ, de Jong R, Lee M-M, Nylin S, Pierce NE, Sperling FAH, Vila R, Darren AD, Zakharov E (2005) Synergistic effects of combining morphological and molecular data in resolving the phylogeny of butterflies and skippers. Proc R Soc B 272:1577-1586

Wedell N (1996) Mate quality affects reproductive effort in a paternally investing species. Am Nat 148:1075-1088

Wilkinson GS, South JM (2002) Life history, ecology and longevity in bats. Aging Cell 1:124-131 